\title{
BANDWIDTH AND GAIN ENHANCEMENT IN HELICAL ANTENNA FOR KU BAND AND SATELLITE COMMUNICATION APPLICATIONS
}

\author{
SSSR Rao ${ }^{1}$, T.V.Ramana ${ }^{2}$, E Sarva Rameswarudu ${ }^{3}$ \\ ${ }^{1}$ Research Scholar, Department of ECE, GITAM University, Vizac, AP, India \\ ${ }^{2}$ Associate Professor, Department of ECE, GITAM University, Vizac, AP, India \\ ${ }^{3}$ Assistant professor in Department of ECE in Kakinada Institute of Technology and Science, Divili, AP, India
}

\begin{abstract}
This study implements the design of an axial mode helical antenna for Ku-band satellite communication application. The paper presents design and optimization of helical antenna to resonate at $26.60 \mathrm{GHz}$ with $45.8 \mathrm{~dB}$ return loss and the antenna is operating at frequency range of $18 \mathrm{GHz}$. The antenna has a peak gain of 11.39dB. The gain of the helical antennas is increasing by decreasing the spacing between the turns of coil and also the increasing the number of turns in the helical antenna. HFSS simulation tool is used in the designing. It will be measured and simulated return loss, axial-ratio, radiation pattern, and realized gain are presented and discussed.
\end{abstract}

Keywords: helix antenna, Satellite communication, Gain, HFSS.

\section{INTRODUCTION}

Helical antenna is also termed as a helix antenna was invented by john Kraus in 1946[1]. Helical antenna which has always been in demand for wireless communication, satellite communication and space communication because they provide ease of implementation, availability of high gain and circular polarization. Helical antenna had two basic propagation modes[2-3]: the axial mode, which implies that the gain is best along the axis of the helix; and the normal mode, which simply means that the gain is null along the axis of the helix [4-5]. The performance of the helical antennas are depends on the number of turns, pitch and radius of antenna. In the normal mode, the radiation occurs in the plane perpendicular to its axis[6-7]. This type of antenna is used in portable radios and in single side band. In the axial mode the antenna radiates the radio waves in circular polarization and the radiation occurs in the direction of its axis.

\section{DIFFERENT HELICAL ANTENNA DESIGN}

\section{PARAMETERS}

The Proposed antenna Simulated by using HFSS at $\mathrm{Ku}-$ band. The Frequency range of of Ku-band is 12$18 \mathrm{GHz}$. Which is used in wireless communication, missile application, navigation and radar applications etc. The design techniques are also applicable to any frequency ranges, which can be selected according to the designer's wish. The parameters that describe a helix are summarized below and Fig1 shown helical antenna geometry.

The parameters that describes a helix are summarized below $\mathrm{D}=$ Diameter of the helix

$\mathrm{S}=$ Spacing between turns

$\mathrm{N}=$ Number of turns

$\mathrm{C}=$ Circumference of the helix
$\mathrm{A}=$ Total axial length

$\alpha=$ pitch angle

The Axial Ratio of the helix is given by $A R=\frac{2 s \lambda}{\pi^{2} D^{2}}$

The normal mode helix will be circularly polarized if $\mathrm{C}=\sqrt{2 s \lambda}$

The formulae for Half Power Beam Width is $\mathrm{HBPW}=\frac{52}{\propto \lambda \sqrt{\mathrm{NS \lambda}}}$

The formulae for input impedence is $\mathrm{R}=140 \mathrm{C} \lambda \mathrm{ohms}$

The band width of helix is defined as the ratio of upper frequency to lower frequency $\mathrm{BW}=\frac{\mathrm{Fu}}{\mathrm{FL}}$

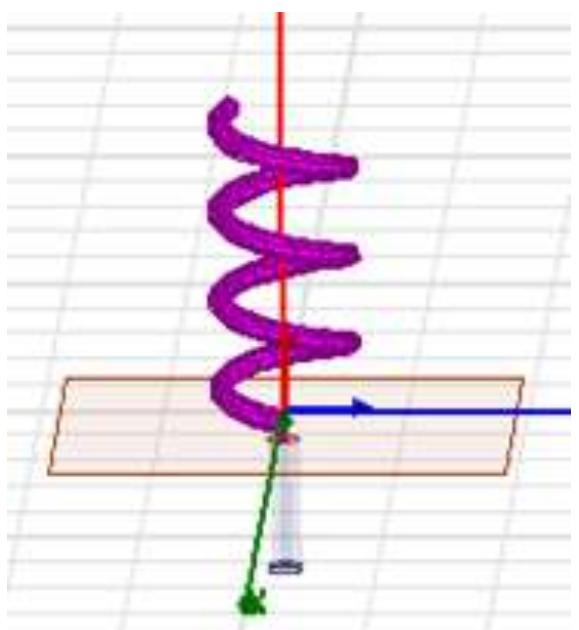

Fig. 1 Geometry of Helical Antenna 


\section{RESULTS}

By observing Fig2.it represents the return loss of helix antenna and it shown resonate at $26.60 \mathrm{GHz}$ with $45.8 \mathrm{~dB}$ return loss and the antenna is operating at frequency range of $18 \mathrm{GHz}$.Fig3. represent smith chart of helical antenna to describe impedance.Fig4. shown Graph for 3D Gain of RHCP helical antenna at Ku-band . Fig5. shown Graph for 3D Gain of LHCP helical antenna at Ku-band .By observing Fig6. and Fig7. they represent Graph for 2D Gain of RHCP helical antenna at Ku-band and Graph for 2D Gain of LHCP helical antenna at $\mathrm{Ku}$-band respectively, which given peak gain LHCP of $11.39 \mathrm{~dB}$ at operating frequency $18 \mathrm{GHz}$.and Fig8 and Fig 9 describes radiation pattern of helix antenna.

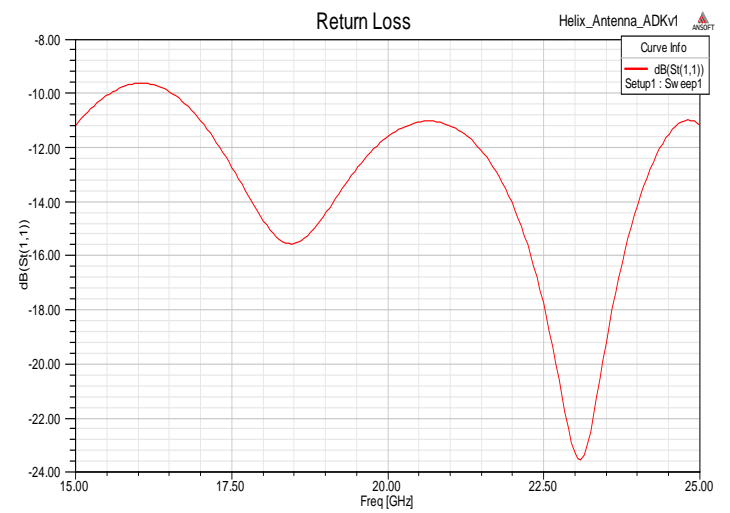

Fig. 2: Graph for Return loss of helical antenna at Ku-band

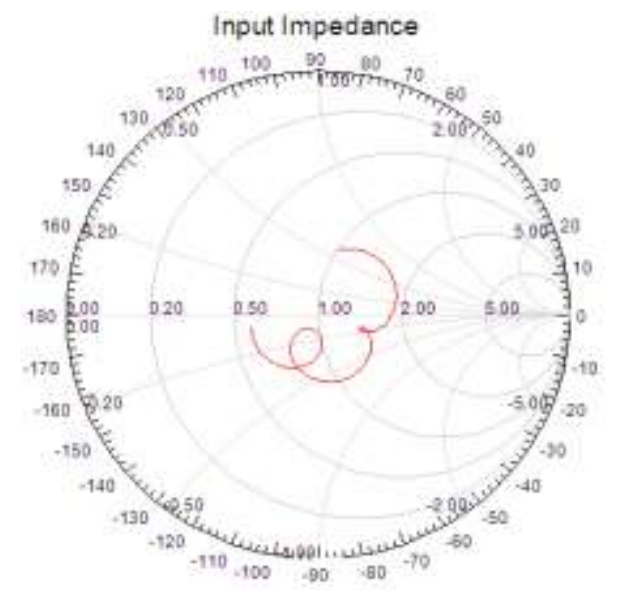

Fig. 3: Smith chart for impedance of helical antenna at $\mathrm{Ku}$ band

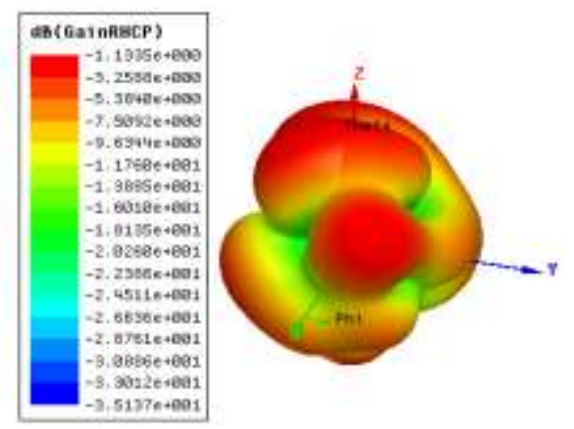

Fig. 4: Graph for 3D Gain of RHCP helical antenna at Kuband

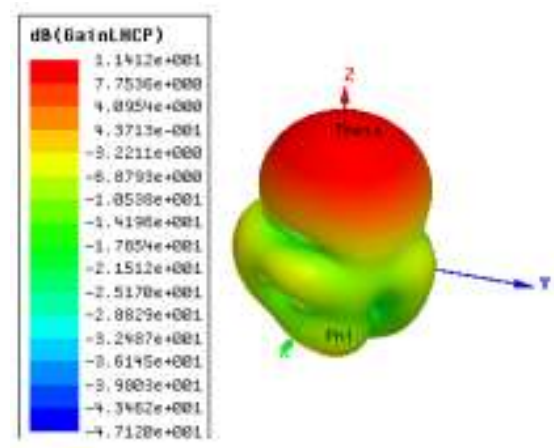

Fig. 5: Graph for 3D Gain of LHCP helical antenna at Kuband

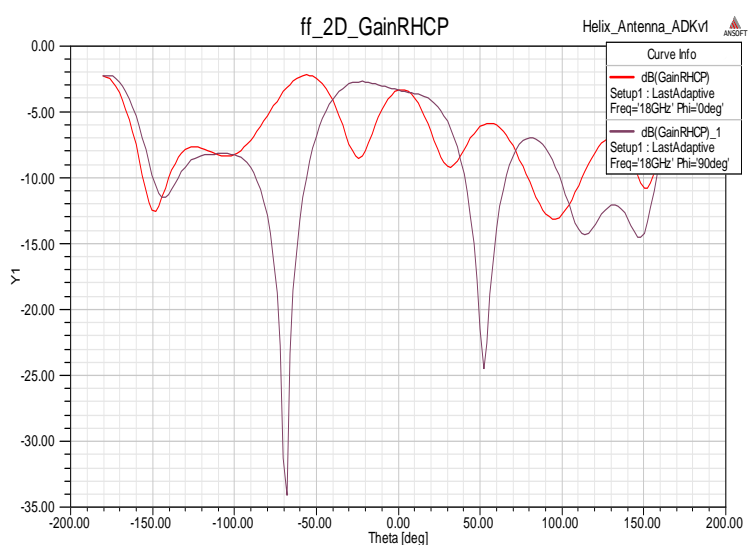

Fig. 6: Graph for 2D Gain of RHCP helical antenna at Kuband

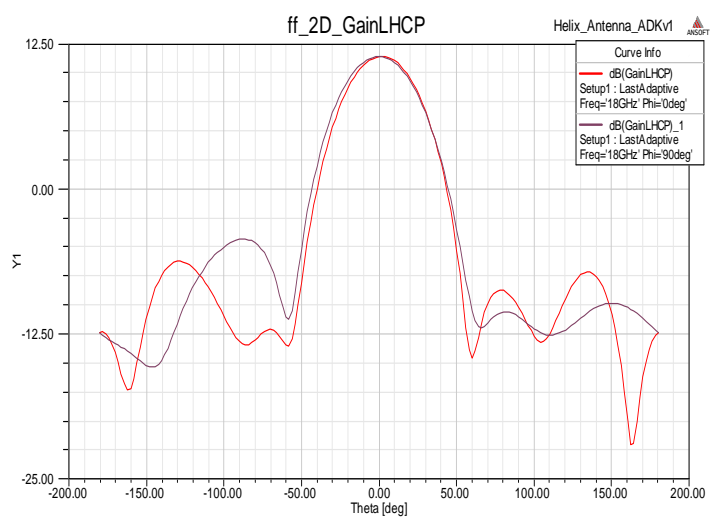

Fig. 7: Graph for 2D Gain of LHCP helical antenna at Kuband

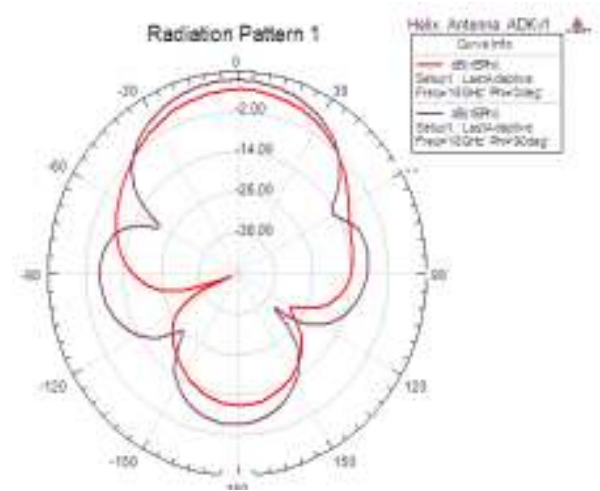

Fig. 8: Graph for polar radiation pattern helical antenna at Ku-band 

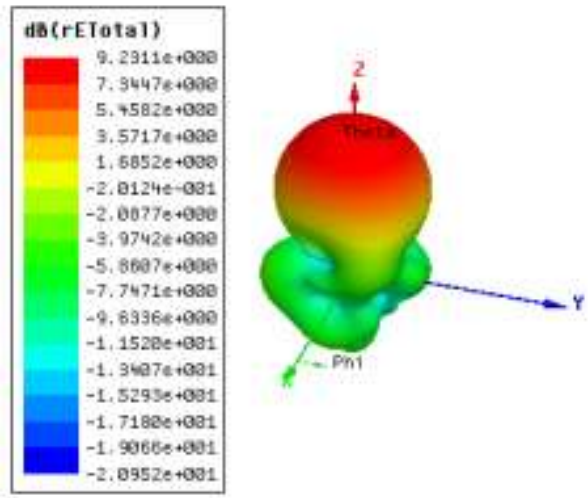

Fig. 9: Graph for radiation pattern helical antenna at $\mathrm{Ku}-$ band

\section{CONCLUSION}

In this paper, helical antenna designed at Ku-band. The paper presents design and optimization of helical antenna to resonate at $26.60 \mathrm{GHz}$ with $45.8 \mathrm{~dB}$ return loss and the antenna is operating at frequency range of $18 \mathrm{GHz}$. The antenna has a peak gain of $11.39 \mathrm{~dB}$, which operated at large bandwidth. The gain of the helical antennas is increasing by decreasing the spacing between the turns of coil and also the increasing the number of turns in the helical antenna. HFSS simulation tool is used in the designing. The designed helical antenna in this simulator, which is placed over the rectangular ground conductor.

\section{ACKNOWLEDGEMENT}

Authors like to express their gratitude towards the department of ECE, GITAM University and management of Kakinada Institute of Technology and Science for their support and encouragement during this work.

\section{REFERENCES}

[1]. M. Hussein, M. Hakkak, Senior Member IEEE, "Design of a Dual-Band Quadrifilar Helix Antenna" IEEE antennas and wireless propagation letters, VOL. 4, 2005

[2]. Muhammad Amin and Robert Cahill, "Effect of Helix Turn Angle on the Performance of a Half Wavelength Quadrifilar Antenna", IEEE microwave and wireless components letters, VOL. 16, NO. 6, June 2006

[3]. Yazad Khan, Ashish Kumar, Jayant Sharma, "GainEnhancement of the Helical Antenna by EffectingTurnspacing", International Journal of Engieering Trendsand Technology (IJETT), Vol. 4, Issue 5, May 2013. [4]. Parminder Singh, Manpreet Kaur, Manju,"Single BandHelical Antenna in Axial Mode", International Journal ofElectronics Communication and Computer Technology(IJECCT) Vol. 2, Issue 6, November 2012.

[5]. Balanis C. A. Antenna Theory Analysis and design. 3rd Edition, John Wiley and Sons Inc, pp.18-22, 2005

[6]. Emerson D.T. The gain of the Axial Mode Helical Antenna.National Radio Astronomy Observatory (NRO++) Antenna Compedium, Volume 4, pp. 64-68. 1995.

[7]. MajaSkiljoZoranBlazevic, Ante Jurisic, Katarina Pandzic. Improving the Helical Antenna Performance by
Changing the Pitch Angle and the Shape of the Helix.IEEE Xplore, Software, Telecommunications and Computer Networks (SoftCOM), 2010 International Conference, 2010. 